\title{
Introduction to the Films
}

Maya Deren

[This text is transcribed from a carbon copy of the original material typewritten by Maya Deren, dated 1945 and titled "Introduction to the Films," from the Maya Deren Collection, Howard Gotlieb Archival Research Centre at Boston University. It is reproduced here by kind permission of the Centre. Slight idiosyncrasies in Deren's typing have been corrected. Elinor Cleghorn would like to thank JC Johnson at the Howard Gotlieb Archival Research Centre for all his help and assistance.]

I is still such a novelty to consider film as an art form, that I would like to point out some rather special problems which are involved in such an approach to film. I would like to begin by recapitulating some basic aesthetic principles, and then relating them specifically to film.

The first characteristic of a true work of art is that is creates a reality and itself constitutes an experience. It does not merely describe something of which we are already fully aware. This new reality consists of elements selected from natural reality and is achieved through the establishment of a new, imaginative relationship between these elements of the natural world.

The creation of this new relationship constitutes the form of the work of art, and thus the form incorporates the intention of the artist. That is, the artist assigns meaning, value and weight to the selected natural elements by giving them a certain position in the work as a whole, and thus their natural values - that is, the value which these elements have in a natural reality - are transformed into new values which are assigned them by the artist according to the function he gives them in the context which he creates.

Translated into cinematic terms, this would mean that the elements of natural reality, selected and registered by the lens, should be given new meaning by a manipulation behind the lens - manipulation of the camera mechanism (its varying speeds, etc.) of the movement of the camera as a body, and in the cutting and editing of the film afterwards. For if we are to accept the mechanical similarity between the lens and the eye as the basis of an analogy between the camera and a human being, then we must extend that analogy to include the brain behind the eye, which gives meaning to the material which the eye registers, and to include also the body, whose movements are motivated by the meaning which the brain assigns to the material which the eye registers. Unfortunately, in most films, there is no such extension of the analogy. The creativity of the camera is usually limited to the selection of the elements from the natural reality, but there is little manipulation of them beyond that. They are merely re-combined on film in an effort to recapitulate the natural reality itself, a reality which is usually more convincing and more rich in its natural state. 
This new unfortunate tradition of recapitulating natural reality rather than creating new ones - a tradition for which the commercial film industry is responsible-creates a special problem for the art film in its relation to an audience unaccustomed to the products of the film industry. For instead of assuming that they will be confronted by new realities, and preparing themselves to receive those new realities with the same un-selfconscious receptivity which they bring to other art forms, they seek to recognize, in the films, some natural reality which they can subject to a personal interpretation, as they do with natural phenomenon.

For this is the special problem of cinema. Its great strength, its great ability to convince, lies in its resemblance to natural reality. When we see a real tree in a scene, we believe the event under the tree to be as real and as natural as true. Thus, by a delicate manipulation of such natural elements - a manipulation which succeeds in retaining their realityone can create a new reality, based on a new relationship of those elements, which will partake of "the truth" of nature. This is, in a sense, the secret of those Nazi " documentaries" which, employing the same material, and in many cases the very same scenes as are available to the documentarists of other ideologies, are able to so relate them as to convincingly create a "truth" which is, actually, untrue.

The realities which film as an art form seeks to convey may be as delicate and subtle as are the perceptions in other art forms. And here the potential strength of film-and its resemblance to natural reality - requires of the audience a certain adjustment; for the audience tends to bring towards film that attitude which it exercises towards natural phenomena. Such a natural phenomenon as a sunset, for instance, has no conscious intention, for the revolutions of the earth do not contain conscious purpose. Consequently, the observer or the artist can endow it with whatever emotional meaning-peace, or fear of the oncoming night, or beauty -is appropriate to his personal intention or inclination. But a work of art already incorporates an intention — the intention of the artist-and it is he who has already made a selection from natural reality and has attempted to assign meaning to that selection by his treatment of the elements, not only individually, but by their function and relation to the whole. Consequently the spectator must here, before the works of art where artifice is inescapable, concern himself not with his own creative interpretation of the elements, but with the discovery of the intention of the artist with respect to those elements.

The form as a whole, the contextual logic which endows each of the elements of the work with meaning, is, in a time art such as cinema, revealed only when the work as a whole has been experienced. Only after the experience is complete, and the logic therefore completely delineated, can the individual elements - symbols, characters etc. - be understood according to the intention of the artist in terms of the logic he has created. In other art forms we recognize this. The poem, the dance, the symphony, the painting are all experienced more than once by the serious spectator. The same applies to creative film. That very richness which, in other art forms, continues to reveal more and more of itself each time our attention is given it, is the very element which would be neglected in a film designed to be taken in one performance.

If a self-conscious, critical analysis is exercised in the course of the first viewing of a work of art, or of any experiential reality, it will only result in a distorted interpretation, and will hinder the perception of the artist's intention. For such an analysis would be based 
on the personal logics of the spectator and not upon the logic which the artist seeks to establish. The inevitabilities of a state of anger, for instance, will not seem inevitable if analyzed by a logic of state of calm and repose. Nor can an "objective" logic explain the actions of a man in love. Any analysis of the reason for an emotion can only follow upon the experience but can never induce it. In an appreciation of a work of art, which is, essentially, an experience itself, such an analysis is a completely secondary activity which, at most, justifies that experience in its own terms but can never "explain it," according to an alien logic. 